\title{
Surface modification of mineral filler using nanoparticles for asphalt application
}

\author{
Sergey Inozemtsev ${ }^{1, *}$, and Evgeniy Korolev ${ }^{1}$ \\ ${ }^{1}$ Moscow State University of Civil Engineering, Yaroslavskoe shosse, 26, Moscow, 129337, Russia
}

\begin{abstract}
A model for surface modification of mineral filler in asphalt mixes using nanoparticles which control sorption ability of light fractions of bitumen represented in this research. Colloidal solutions of iron hydroxide (III) and silicic acid sols with $30-40 \mathrm{~nm}$ particles size were used as an active functional layer for surface modification of mineral filler. In this study were determined an effective boundary values for nanomodified filler based on morphological characteristics of asphalt surface. It was demonstrated, that the development of an effective nanomodified filler required using a high porosity mineral component, modified with nanolayer (less than $100 \mathrm{~nm}$ ) of an active component.
\end{abstract}

\section{Introduction}

Asphalt concrete is the most common material used for the construction of highways. The quality of the pavement road surface and its durability is determined by the ability of asphalt concrete to resist weather and climate factors and dynamic mechanical loads of road transport during the entire operational cycle. The interaction intensity of the asphaltconcrete mixture components and the phase formed as a result of this process determine the durability of the material. The parameters of the asphalt-concrete structure are influenced by the distribution of bitumen along the surface of mineral components, the packing density of the mineral aggregate, the adhesion force of bitumen with the surface of mineral material grains as well as by the properties of the primary components. It is obvious that the quality of asphalt concrete is largely determined by the state and properties of the binder in pellicles that are formed on the surface of grains of mineral components [1...3].

The nature of the interaction of bitumen and the surface of the mineral powder particles has a particular importance, since its surface area is more than $90 \%$ of the total surface area of the particles of asphalt concrete mineral components. The ability of the material structure to resist external factors depends on the activity of the interaction at the "bitumen-porous filler" interphase [4...7], since the bitumen is structured on the surface of the mineral component, the intensity of which is determined by the surface area of contact and the adsorption capacity of the mineral component, especially mineral filler.

\footnotetext{
* Corresponding author: inozemcevss@mgsu.ru
} 
Thus, to obtain the initial structure of asphalt concrete with the desired properties, it is necessary to develop management methods of sorption processes on the phase boundary "bitumen - filler".

Common practice to control the interaction processes between mineral filler is the surface activation of its grains of various kinds by modifying agents [8,9]. Filler surface activation with the filler joint grinding technology application with the organic compounds allows obtaining the material, providing the value decrease of the asphalt binder properties [8...12]. However, the effectiveness of the use of these fillers is accompanied by the complication of the production technology and increase the cost of the final product.

These facts emphasize the work on the development of methods to control the sorption processes on the phase boundary "bitumen - filler".

\section{Theoretical part}

In accordance with micellar theory, bitumen is represented by a colloid system in which asphaltenes surrounded by a shell of resins are a dispersed phase, and oil fractions are a dispersion medium [13...15]. In such a system, an inert oil membrane blocks the most chemically active functional groups that form part of asphaltene-resins structures [16 ..21].

When bitumen is combined with a mineral material having a porous structure, a redistribution of the bitumen group composition occurs, as a result of which light fractions enter the intrapore area of particles during the diffusion process, and asphaltene-resinous structures concentrate on the grain surface, which leads to the formation of strong bituminous films. These processes are described by the Poiseuille' law for a cylindrical capillary [20]:

$$
\Delta P=\frac{2 \sigma}{R_{c}} \cos (\theta)-P_{0},
$$

where $2 \sigma \cdot \cos (\theta) / R_{c}$ - capillary pressure, according to Laplace's law, Pa; $\sigma$ - capillary tension of bitumen light fractions, N/m; $R_{c}$ - capillary radius, $\mathrm{m} ; P_{0}=101325 \mathrm{~Pa}-$ atmosphere pressure (760 $\mathrm{mm} \mathrm{Hg}$.) [21].

The geometric data of the capillary depend on the parameters of the pores space of the mineral component particle and its geometric data. Pores volume (of capillaries) can be presented as $V_{p}=\frac{\varepsilon \cdot d_{f}^{3}}{6}$, so that $V_{p}=2 \pi N_{c} R_{c} L_{c}$ (where $\varepsilon-$ volume fraction of pores; $d_{f}$ - diameter of the mineral particle grain (carrier); $N_{c}$ - number of capillaries; $R_{c}, L_{c}$ - radius and length of capillary).

By assuming $L_{c}=\frac{d_{f}}{2}$ the number of capillaries will be:

$$
N_{c}=\frac{\varepsilon d_{f}^{2}}{3 R_{c}^{2}}
$$

To find the boundary values of the diameter of mineral component particles, we introduce the coefficient (modulus of the open surface):

$$
M_{s}=\frac{S_{f}}{V_{f}}
$$

With $S_{f}=\pi d_{f}^{2}+2 \pi N_{c} R_{c} L_{c}$ and provided that $L_{c}=\frac{d_{f}}{2}, L_{c}=\frac{d_{f}}{2}$ modulus of surface will be: 


$$
M_{s}=\frac{6}{d_{f}}+\frac{2 \varepsilon}{R_{c}}
$$

Then

$$
d_{f}=\frac{6}{M_{s}-\frac{2 \varepsilon}{R_{c}}} .
$$

As $\varepsilon=\varepsilon_{\max }$ the maximum value of the open surface modulus is:

$$
M_{s, \max }=\frac{2 \varepsilon_{\max }}{R_{c}}
$$

then:

$$
d_{f}=\frac{6 R_{c}}{2\left(\varepsilon_{\max }-\varepsilon\right)} .
$$

It follows that, when using dense mineral components, a significant grinding is necessary for their application in asphalt concrete technology.

Reducing the geometric data of the capillaries naturally increases the value of $Q$. Such a change in $\mathrm{Q}$ can be realized practically by arranging a porous membrane with capillary characteristics $l_{c}$ and $r_{c}$ on the surface of the mineral particle.

In this case, a material is formed that consists of two parts: an active component that regulates the sorption process of light bitumen fractions and a mineral component that is the carrier of the active component (Figure 1).

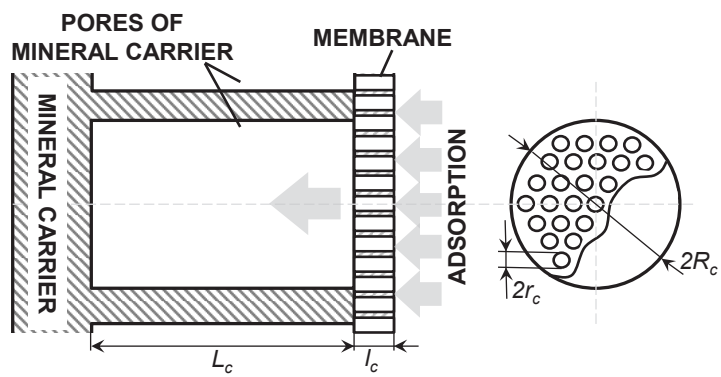

Fig. 1. Nanomodified filler model and capillary surface pattern

Obviously, the criterion for the effectiveness of this mechanism is the condition $\frac{Q_{n}}{Q}>>1$, where $Q_{n}$-the flow of light fractions passing through the capillaries of the modifier active component.

$Q_{n}$ can be write as:

$$
Q_{n}=N_{c}^{n} \frac{\left(\frac{2 \sigma}{r_{c}} \cos (\theta)-P_{0}\right) \cdot \pi \cdot r_{c}^{4}}{8 \cdot \eta \cdot l_{c}},
$$

where $N_{c}^{n}$ - the quantity of capillaries, placed on an area corresponding to the cross section of a capillary with a diameter $2 R_{c}$ (Figure $2, \mathrm{~b}$ ):

$$
N_{c}^{n}=\varphi\left(\frac{R_{c}}{r_{c}}\right)^{2}
$$

where $\varphi$ - packing density of capillaries with a diameter $r_{\mathrm{K}}$ on the surface. 
From here it follows that:

$$
\frac{Q_{n}}{Q}=\varphi \frac{\left(\frac{2 \sigma}{r_{c}} \cos (\theta)-P_{0}\right) \cdot L_{c} \cdot r_{c}^{2}}{\left(\frac{2 \sigma}{R_{c}} \cos (\theta)-P_{0}\right) \cdot l_{c} \cdot R_{c}^{2}}
$$

When introducing the coefficients $k_{R}=\frac{R_{c}}{r_{c}}$ и $k_{R}=\frac{L_{c}}{l_{c}}$ the formula takes the form:

$$
\frac{Q_{n}}{Q}=\varphi \frac{\left(\frac{2 \sigma}{r_{c}} \cos (\theta)-P_{0}\right)}{\left(\frac{2 \sigma}{R_{c}} \cos (\theta)-P_{0}\right)} \cdot \frac{k_{L}}{k_{R}^{2}} \text { or } \frac{Q_{n}}{Q}=\varphi \frac{\left(\frac{2 \sigma}{r_{c}} \cos (\theta)-P_{0}\right)}{\left(\frac{2 \sigma}{r_{c}} \cos (\theta)-k_{R} P_{0}\right)} \cdot \frac{k_{L}}{k_{R}}
$$

We establish the boundary values $R_{c}, r_{c}, L_{c}, l_{c}$ of the modifier. The value of $R_{c}$ is determined from the equation:

$$
\frac{2 \sigma}{r_{c}} \cos (\theta)-P=0
$$

Then

$$
R_{c}=\frac{2 \sigma \cos (\theta)}{P_{0}}
$$

At $\sigma=0.0375 \mathrm{~N} / \mathrm{m}, P_{0}=101325 \mathrm{~Pa} R_{c, \max }=740 \mathrm{~nm}$. $r_{c, \max }$ will be defined from the equation:

$\frac{2 \sigma}{r_{c}} \cos (\theta)-k_{R} P_{0}=0 \frac{2 \sigma}{r_{c}} \cos (\theta)-k_{R} P_{0}=0$, thus, $r_{c}=\frac{2 \sigma \cos (\theta)}{k_{R} P_{0}}$.

Calculated results of $r_{c, \max }$ are illustrated in Figure 2.

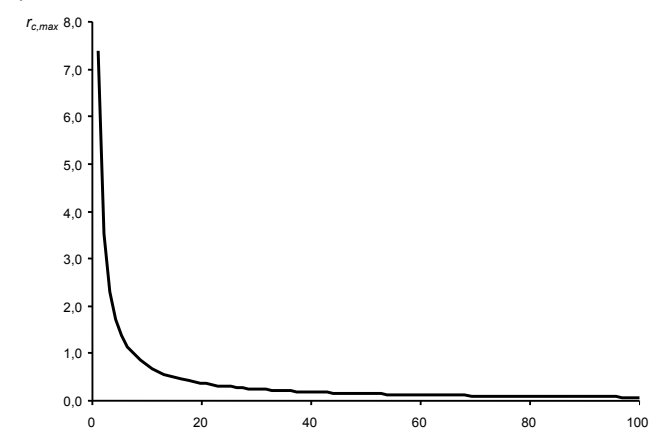

Fig. 2. Dependence $r_{\mathrm{K}, \max }=f\left(k_{R}\right)$ (if $\left.\sigma=0.0375 \mathrm{~N} / \mathrm{m}, P_{0}=101325 \mathrm{~Pa}\right)$

The thickness of the active layer on the surface of the mineral carrier $l_{c}$ is measured under the assumptions: $\frac{Q_{n}}{Q}=1 ; k_{R}=1$ и $k_{L}=\frac{L_{c}}{l_{c}}=\frac{d_{f}}{2 l_{c}}$. Therefore maximum layer thickness: $l_{c, \max }=\frac{\varphi d_{f}}{2}$.

Calculated results of $l_{c}$ where $\varphi \in I[0.52 ; 0.74]$ are illustrated in Figure 3 . 


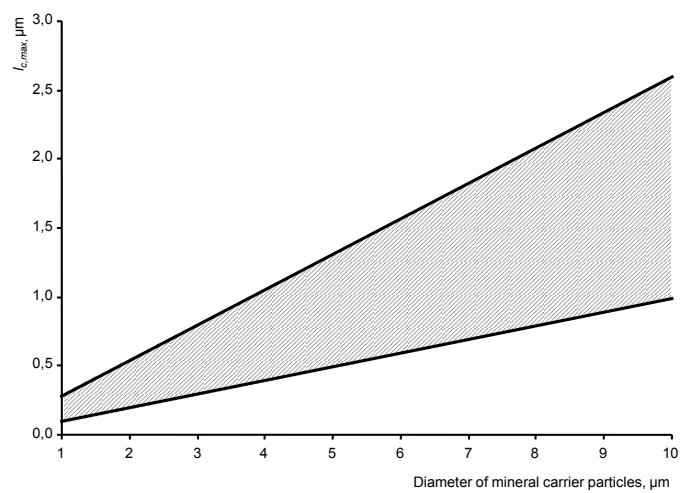

Fig. 3. Layer thickness dependence of the active component $l_{c, \max }$, on the diameter of the carrier particles $d_{f}$

Taking into account the obtained boundary conditions for the surface modifier pattern, it is possible to determine the preferred parameters of the mineral components used as the carrier of the active component, as well as its geometric data.

By assuming that there are two materials with the same chemical composition (in this case, $\theta=$ const), but with a different porosity: $\varepsilon_{1}=0.75$ and $\varepsilon_{2}=0.3$. If $R_{c}=a R_{c, \max }(a<1)$ the maximum diameters of the carrier particles are $d_{f, 1}=4.29 \mu \mathrm{m}$ and $d_{f, 2}=4.11 \mu \mathrm{m}$. Hence $R_{c, 1}=6.78 \mathrm{~nm}, R_{c, 2}=4.11 \mathrm{~nm}$. Significant increase in the efficiency of the modifier is observed only when the thickness of the active component layer is less than $100 \mathrm{~nm}$.

Provided that $Q_{n} / Q=$ const, $k_{R}=1, k_{l, 1}=23.3$ and $k_{l, 2}$ values $=23.2$, which correspond to the thickness of active component layer $l_{c, 1}=92 \mathrm{Nm}, l_{c, 2}=88 \mathrm{Nm}$. Result analysis shows that in order to achieve a given efficiency of the filler on the mineral material basis with less porosity, surface activation requires due to more fine grinding and a thinner layer of active component applying. For porous filler, active component has a smaller effect on the

sorption process, so its thickness can be increased. This allows organizing the production of such a modifier using less energy-consuming technologies.

\section{Results and discussion}

In accordance with the presented model, filler from diatomite with the functional layer on the surface was produced, in which capacity the nanoscale modifier on ferric hydroxide sol (III) and silicic acid basis [22, 23] was used.

The technology of nanomodified filler preparation includes the following processes:

- mineral component preparation (drying and milling);

- mixing of the mineral component with the active component in the mixer;

- heat treatment;

- grinding of heat treatment product.

The active component effect on the carrier surface was assessed by the bitumen-mineral binder property change with application of BND 60/90 bitumen of JSC Moscow Oil Refinery's production, which conforms to GOST 22245-90 "Construction bitumen. Specifications" requirements and volumetric filling degree of 0.2 : depth of needle penetration at 0 and $25{ }^{\circ} \mathrm{C}$, softening temperature, brittleness temperature, and stability properties after aging (Table 1). 
Table 1. The bituminous binder properties with application of nanomodified filler before and after aging.

\begin{tabular}{|c|lc|c|c|c|c|}
\hline \multirow{2}{*}{$\begin{array}{c}\text { Ser. } \\
\text { No }\end{array}$} & \multicolumn{2}{|c|}{ Indicator name } & \multicolumn{3}{|c|}{ Indicator values for fillers } \\
\cline { 4 - 7 } & & \multicolumn{2}{|c|}{ Diatomite } & \multicolumn{2}{c|}{$\begin{array}{c}\text { Nanomodified } \\
\text { diatomite }\end{array}$} \\
\cline { 4 - 7 } & & before & after & before & after \\
\hline 1 & $\begin{array}{l}\text { Depth of needle penetration at a } \\
\text { temperature of } 25{ }^{\circ} \mathrm{C}, 0.1 \mathrm{~mm}\end{array}$ & 44.1 & 41.7 & 50.1 & 37.7 \\
\hline 2 & $\begin{array}{l}\text { Depth of needle penetration at a } \\
\text { temperature of } 0{ }^{\circ} \mathrm{C}, 0.1 \mathrm{~mm}\end{array}$ & 26.2 & 27.0 & 31.5 & 25.0 \\
\hline 3 & Softening temperature, ${ }^{\circ} \mathrm{C}$ & 57.4 & 58.4 & 57.3 & 63.2 \\
\hline 4 & Brittleness temperature, ${ }^{\circ} \mathrm{C}$ & -17.5 & -19.5 & -19.0 & -17.0 \\
\hline 5 & Ductile temperature range, ${ }^{\circ} \mathrm{C}$ & 74.9 & 77.9 & 76.3 & 80.2 \\
\hline
\end{tabular}

The assessment of the surface modification complex effect on the properties that characterize the material quality was conducted with the use of multi-objective optimization methods $[24,25]$. The effectiveness of nanomodifier was assessed by its effect on the structural strength of the bitumen-mineral binder. The ability of bitumen binder to resist mechanical load is assessed by penetration value both at positive temperatures and at $0{ }^{\circ} \mathrm{C}$, and the temperature factor - at brittleness and softening temperature. It is important to consider the direction property change and requirements to the values, formulated on the practical experience basis. For example, it has been established that it is necessary to increase the operation temperature range by increasing the absolute values of brittleness and softening temperature. It is also important that the values of these properties were also more than target values. It is also necessary to ensure the stability of property values after ageing. Based on the above, the following specific criteria were developed, for which the specifications of bitumen, as the reference, were accepted on the diatomite basis without the active layer on the grain surface.

The criterion, characterizing the depth of needle penetration (penetration) at $25{ }^{\circ} \mathrm{C}$ and $0{ }^{\circ} \mathrm{C}$ before and after the modified binder samples aging by nanomodifier, is equal to:

$$
k_{p}=\frac{1}{2} \cdot \frac{\Delta P}{\Delta P^{\prime}} \cdot\left(\frac{\Delta P}{\Delta P_{0}}+\frac{\Delta P^{\prime}}{\Delta P_{0}^{\prime}}\right) \cdot \frac{P_{0(25)}}{P_{(25)}} \cdot \frac{P_{(0)}}{P_{0(0)}},
$$

where $\Delta P=P_{(25)}-P_{(0)}, \Delta P^{\prime}=P_{(25)}^{\prime}-P_{(0)}^{\prime}, \quad \Delta P_{0}=P_{0(25)}-P_{0(0)}, \Delta P_{0}^{\prime}=P_{0(25)}^{\prime}-P_{0(0)}^{\prime}$, $P_{(25)}, P_{(0)}-$ depth of needle penetration at $25^{\circ} \mathrm{C}$ and $0{ }^{\circ} \mathrm{C}$, accordingly, before the aging; $P_{(25)}^{\prime}, P_{(0)}^{\prime}$ - depth of needle penetration at $25^{\circ} \mathrm{C}$ and $0{ }^{\circ} \mathrm{C}$, accordingly, after the aging; $P_{0(25)}, P_{0(0)}-$ depth of needle penetration into the check sample at 25 and $0{ }^{\circ} \mathrm{C}$, accordingly, before the aging; $P_{0(25)}^{\prime}, P_{0(0)}^{\prime}$ - depth of needle penetration into the check sample at 25 and $0{ }^{\circ} \mathrm{C}$, accordingly, after the aging.

The temperature criterion, taking into accounts the change of brittleness and softening temperatures before and after modifier binder samples aging, will be equal to:

$$
k_{p}=\frac{1}{2} \cdot \frac{\Delta T}{\Delta T^{\prime}} \cdot\left(\frac{\Delta T}{\Delta T_{0}}+\frac{\Delta T^{\prime}}{\Delta T_{0}^{\prime}}\right) \cdot \frac{T_{F}}{T_{F(0)}} \cdot \frac{T_{S}}{T_{S(0)}},
$$

where $\Delta T=T_{S}-T_{F}, \Delta T^{\prime}=T_{S}^{\prime}-T_{F}^{\prime}, \Delta T=T_{S(0)}-T_{F(0)}, \Delta T^{\prime}=T_{S(0)}^{\prime}-T_{F(0)}^{\prime}-$ softening and brittleness temperatures of binder samples, modified by nanomodifiers, before and after aging, accordingly; $T_{S}, T_{F}, T_{S(0)}, T_{F(0)}$ - softening and brittleness temperatures of blended check samples before and after aging, accordingly. 
An integrated assessment of the nanomodifier effect was conducted by the generalized criterion:

$$
k_{e f}=\sum_{i=1}^{n} \alpha_{i} \cdot k_{i} \rightarrow \max
$$

where $\alpha_{i}$ - weight coefficient $\sum_{i=1}^{n} \alpha_{i}=1 ; k_{i}-$ partial criterion, characterizing certain properties of the material.

Table 2. The calculation results of the generalized criterion of the surface nanomodifier efficiency

\begin{tabular}{|l|c|c|c|}
\hline \multirow{2}{*}{ Mineral component name } & \multicolumn{3}{|c|}{ Weight coefficient value } \\
\cline { 2 - 4 } & $\alpha_{1}=0.75$ & $\alpha_{1}=0.5$ & $\alpha_{1}=0.25$ \\
$\alpha_{2}=0.25$ & $\alpha_{2}=0.5$ & $\alpha_{2}=0.75$ \\
\hline Diatomite (check) & 1.00 & 1.00 & 1.00 \\
\hline Nanomodified diatomite & 1.16 & 1.27 & 1.37 \\
\hline
\end{tabular}

The calculation results of the generalized criterion of efficiency (Table 2) show that efficiency increasing of the porous mineral filler is possible through the use of surface nanomodifier on the ferric hydroxide sol (III) and silicic acid basis.

To confirm that the effect of the surface nanomodification is a consequence of sorption processes and not chemical processes on the interphase boundary "bitumen - filler", the pore restructuring of diatomite after nanomodifier treatment was investigated. Using the nitrogen porosimetry DFT method, it has been established that the average diameter of the pores with sizes less than $20 \mathrm{~nm}$ after the treatment does not change significantly and is as follows $3.6 \mathrm{~nm}(\mathrm{kR}=1)$, and their overall volume increases by $30 \ldots 40 \%$.

The obtained data correlate with the previously obtained results in other works. Adjustable porosity facilitates the diffusion of bitumen light fractions inside the grains of mineral material with their further desorption [25...30]. The presence of ferriferous materials on the surface of the mineral filler grains increases binder aging resistance [31].

To establish the nature of the interaction between bitumen and filler, the research using IR spectroscopy was conducted.

Comparison of the IR spectra shows that the new maximum emergence is not observed, and there are no significant differences in the major maximum location. This suggests that in interaction of bitumen with nanomodified filler there are processes, driven by the physical adsorption, which leads to the redistribution of the bitumen components.

\section{Conclusion}

1. An effective model of adsorption processes management of the interaction between bitumen and mineral powder was developed, which allows determining the component geometrical characteristics of: carrier and active functional layer as a membrane.

2. Bitumen concrete cross-linking management is possible through the redistribution of bitumen light fractions due to their physical adsorption by the mineral filler, which contains nanolayer of physically active component.

3. Based on the physical principles mineral admixture on the basis of diatomite and nanoscale surface modifier was produced that provides the increasing of endurance period to $37 \%$.

This work was financially supported by the Ministry of Education and Science (state task \#7.6250.2017/8.9). 


\section{References}

1. A.F. Frolov, E.A. Frolova, V.N. Ovchinnikova, V.V. Vasil'eva, Chem. and Tech. of Fuel and Oils, 19, 415-419 (1983)

2. O. Portillo, D. Cebon, Mod. J. of Mater. in Civ. Eng., 25 (10), 1403-1414 (2013)

3. J. Long, L. Zhang, Z. Xu, J.H. Masliyah, Langmuir 22 (21), 8831-8839 (2006)

4. E.V. Korolev, V.A. Beregovoy, A.N. Bormotov, A.I. Eremkin, Works of international conference Concrete durability: achievement and enhancement». England, Scotland, un. Dundee, 345-356 (2008)

5. A.P. Proshin, E.V. Korolev, S.A. Boltyshev, O.V. Koroleva, J. News of Higher Educ. Inst. Constr. 3, 32-36 (2005)

6. A.I. Garkina, A.M. Danilov, E.V. Korolev, J.1 Rev. of Appl. and Ind. Math. 15, 3, 459460 (2008)

7. R. Muniandy, Eltaher Aburkaba, R. Yunus, H. Hamid and H. Salihudin, Asian J. of Appl. Scien., 5, 522-537 (2012)

8. V.V. Alekseenko, Y.V. Saltanova, Vestnik nauki i obrazovaniya Severo-Zapada Rossii, 2, 8-12 (2016)

9. J. Li, A. Q. Zhang, Appl. Mech. and Mat., 174-177, 821-825 (2012)

10. V.S. Prokopets, E.A. Bedrin, Mechanoactivation technology for obtaining mineral binder based on acid ash CHP: textbook (Omsk, SibADI, 2003)

11. A.I. Trautvain, V.V. Yadykina, A.M. Gridchin. Build. Mat., 12, 81-83 (2010)

12. Yu. V. Pokonova, Chem. and Tech. of Fuels and Oils. 43, 4, 330-332.

13. J. Graham, C.R.M. Butt, R.B.W. Vigers, Sub-surface charging, a source of error in microprobe analysis. X-Ray Spectrometry. 13, 3, 126-133 (1984)

14. P. Redelius, H. Soenen Relation between bitumen chemistry and performance. Fuel. 43 (2014)

15. A. Rosinger, Beiträge zur Kolloidchemie des Asphalts. Kolloid-Zeitschrift, 15, 177 179 (1914)

16. N.V. Gornaev, J. News of Higher Educ. Instit. Construction and architecture, 12, 137139 (1967)

17. L.M. Gohman, Highway magazine, 7, 21-23 (1987)

18. J-F. Masson, Terry Price, Peter Collins Energy Fuels, 15 (4), 955-960 (2001)

19. M. Subramanian, M.D. Deo, F.V. Hanson. Journal of Chromatographic Science. 34, 20-26 (1996)

20. S.P. Sutera, R. Skalak,. Ann. Rev. of Fl. Mech. 25, 1-19 (1993)

21. A.P. Babichev, N.A. Babushkina, A.M. Bratkovsky. Physical values: Directory. M.: Energoatomizdat. 1232 (1991)

22. A.N. Grishina, E.V. Korolev, Vestnik MGSU, 10, 159-165 (2012)

23. E.V. Korolev, A.N. Grishina, Building materials, 2, 30-33 (2013)

24. Yu.M. Bazhenov and et. al. System analysis in building materials science: monograph. Education and Science Russ. Federation (Moscow, MGSU. 2012)

25. A.N. Bormotov, I.A. Proshin, E.V. Korolev Mathematical modeling and multicriteria synthesis of composite materials. (Penza, PGTA, 2011) 
26. S.M. Aldoshin, E.R. Badamshina, A.A. Grishchuk, A.E. Tarasov, Y.I. Estrin, R.F. Ganiev, S.R. Ganiev, V.P. Kasilov, D.V. Kurmenev, A.P. Pustovgar, Journal of Machinery Manufacture and Reliability, 44(3), 271 (2015)

27. Olof Kristjansdottir Warm Mix Asphalt for Cold Weather Paving. A thesis submitted in partial fulfillment of the requirements for the degree of Master of Science in Civil Engineering (University of Washington, 2006)

28. V.S. Lesovik, V.S. Prokopets, P.A. Boldyrev, Build. mater. 8, 44-45 (2005)

29. D.I. Chernousov, S.E. Scherbina Scien. and techn. in the road ind., 2, 34-35 (2009)

30. L.E. Svintitskikh, T.N. Shabanov, A.A. Klusiv, V.N. Ageykin, Build. Mater., 9, 32-33 (2004)

31. V.V. Yadykina, A.V. Vysotsky. Corrosion: materials, protection, 6, 43-45 (2004) 